\title{
Tubulopapillary Carcinoma of the Mammary Gland in a Mare
}

\author{
Jair Alves Ferreira Júnior', Saulo Petinatti Pavarini², Marilúcia Campos dos Santos ${ }^{3}$, Karla Alvarenga Nascimento', \\ Pedro Miguel Ocampos Pedroso' ${ }^{1}$ \& Juliana Targino Silva Almeida e Macêdo'
}

\begin{abstract}
Background: Mammary gland neoplasia are often observed in bitches and cats, rarely in cows, goats, sheep, sows, and mares. Among the neoplasia that affect mares, breast tumors are rare, as they occur more frequently in older animals. In horses, mammary gland tumors occur more frequently in older animals. In this species there are reports of cases describing carcinomas and adenocarcinomas and several subtypes. Mammary neoplasms in equines tend to be locally aggressive and promote metastases to the regional lymph nodes and other organs, including the lungs, and may cause pleural effusion. The aim objective of the present case report was to describe the clinical-pathological and immunohistochemical findings of a tubulopapillary carcinoma of the mammary gland in mare.

Case: Was received a biopsy of a tumor mass of the mammary gland of a 15-year-old Quarter Horse mare. According to the veterinarian, the mare presented an increase in volume with ulceration of the mammary gland three months before the biopsy. Macroscopically, the mass was firm to the cut with white surface measuring $12 \times 12 \mathrm{~cm}$. The fragment was fixed in $10 \%$ formalin, routinely processed for histology, paraffin embedded, and stained with hematoxylin and eosin. Microscopically, we observed proliferation of epithelial neoplastic cells arranged in tubules and papillary projections, some with two to three layers of cells. Neoplastic cells had oval, moderate and distinct cytoplasm. The nuclei were rounded with dense chromatin and an apparent nucleolus. There were two figures of mitosis per field of high magnification. Proliferation of neoplastic cells invaded adjacent tissues, and in lymph vessels of the region, neoplastic cells were observed as well as inflammation in adjacent tissue. In addition, the breast fragment was submitted to the immunohistochemistry technique using anti-pancytokeratin and anti-vimentin antibody. In immunohistochemistry for pancytokeratin, there was immunoreactivity with marked cytoplasm in neoplastic epithelial cells. In immunohistochemistry for vimentin, there was cytoplasmic labeling in cells of the supporting tissue (fibroblasts and endothelial cells). After approximately six months of the initial diagnosis, the mare died.

Discussion: The diagnosis of tubulopapillary carcinoma of the mammary gland in a mare was based on the clinicalpathological and immunohistochemical findings. In mares, descriptions of breasts neoplasia are uncommon and found in animals aged over 12 years. In a study carried out in slaughterhouses in France, with approximately 40,000 horses slaughtered, only 45 breast neoplasms $(0.11 \%)$ were observed, most of them consisting of carcinomas. In these equines, the absolute incidence of neoplasia of the reproductive system increases with age and tumors generally appear as deep, multifocal, and ulcerating skin nodules. Thus, important differential diagnoses include chronic mastitis and prepartum breast edema. In mares with neoplasia of the mammary gland, unilateral or bilateral volume increase, pain, warm area, redness and suppurative serous discharge are frequently observed. There are also reports of skin ulceration or necrosis. In the present report, the mare showed increased volume of the mammary gland, with focal hyperthermia, fistulated area and serum-blood secretion. The literature suggests a reserved prognosis for any mare presenting mammary neoplasia. Histopathology and immunohistochemistry were fundamental for the diagnosis of tubulopapillary carcinoma of the mammary gland in the present study. Mammary neoplasiss in mares are rare, but should be considered in the diagnosis of mammary pathologies in this species.
\end{abstract}

Keywords: equine, neoplasia, mammary gland, immunohistochemistry. 


\section{INTRODUCTION}

Mammary gland neoplasms are frequently observed in bitches and cats, and rarely in cows, goats, sheep, sows and mares [2,9]. Among the neoplasms that affect mares, tumors of the mammary glands are rare $[7,8,15]$, as well as tumors of the oviduct, uterus, cervix and vagina, in contrast to tumors of the ovary and external genitalia which are more common [8]. In equines, breast tumors occur more frequently in older animals. In this species, there are reports of cases describing carcinomas and adenocarcinomas, and several subtypes, including solid, papillary, ductal, invasive ductal and invasive micropapillary carcinomas. Mammary neoplasms in equines tend to be locally aggressive and promote metastases to the regional lymph nodes and other organs, including the lungs, and may cause pleural effusion [6]. The aim of the present work is to describe the clinical-pathological and immunohistochemical findings of a case of tubulopapillary carcinoma of the mammary gland in mare.

\section{CASE}

Was received a biopsy of a tumor mass of the mammary gland of a 15-year-old Quarter Horse mare. According to the veterinarian, the mare presented an increase in volume with ulceration of the mammary gland (Figure 1) three months before the biopsy. Physical examination showed edema in the inguinal region, with firm mass palpation affecting all mammary glands, hot, fistulated and with serosanguineous secretion. Macroscopically, the mass was firm to the cut with white surface measuring $12 \times 12 \mathrm{~cm}$. The fragment was fixed in $10 \%$ formalin, routinely processed for histology, paraffin embedded, and stained with hematoxylin and eosin. Microscopically, we observed proliferation of epithelial neoplastic cells arranged in tubules and papillary projections (Figure 2), some with two to three layers of cells. Neoplastic cells had oval, moderate and distinct cytoplasm. The nuclei were rounded with dense chromatin and an apparent nucleolus. There were two figures of mitosis per field of high magnification. Proliferation of neoplastic cells invaded adjacent tissues, and in lymph vessels of the region, neoplastic cells were observed as well as inflammation in adjacent tissue. In addition, the breast fragment was submitted to the immunohistochemistry technique by the streptavidin-biotin-peroxidase method (LSAB Kit Peroxidase Universal, DakoCytomation) ${ }^{2}$ using anti-pancytokeratin (policlonal AE1/AE3, DakoCytomation $)^{2}$, at the dilution of 1:2000 and anti-vimentin antibody (clone V9, DakoCytomation) ${ }^{2}$, at the dilution of 1:100. The chromogen used was 3-3'-diaminabenzidine $(\mathrm{DAB})^{2}$. Sections were counter-stained with Harris haematoxylin ${ }^{1}$. For each antibody, positive and negative controls were used. In immunohistochemistry for pancytokeratin, there was immunoreactivity with marked cytoplasm in neoplastic epithelial cells (Figure 3). In immunohistochemistry for vimentin, there was cytoplasmic labeling in cells of the supporting tissue (fibroblasts and endothelial cells). After approximately six months of the initial diagnosis, the mare died.

The responsible veterinarian performed necropsy, and evidenced neoplastic tissue in the inguinal and kidney lymph nodes, but did not collect organs for histological processing.

\section{DISCUSSION}

The diagnosis of tubulopapillary carcinoma of the mammary gland in a mare was based on the clinical-pathological and immunohistochemical findings. Contrary to what occurs in bitches [4], breast neoplasms are uncommon in herbivores $[5,9,10]$. In a study carried out in slaughterhouses in France, with approximately 40,000 horses slaughtered, only 45 breast neoplasms $(0.11 \%)$ were observed, most of them consisting of carcinomas $[9,10]$. In mares, descriptions of breasts neoplasia are uncommon and found in animals aged over 12 years [10]. In these equines, the absolute incidence of neoplasia of the reproductive system increases with age [8] and tumors generally appear as deep, multifocal, and ulcerating skin nodules [7].

Thus, important differential diagnoses include chronic mastitis and prepartum breast edema [12]. Mammary gland tumors in horses are often diagnosed as mastitis due to their similar presentation [13]. In this case, the onset of tumor development may be confused with mastitis [11]. The occurrence of mastitis in mares is considered low when compared to domestic ruminants. The highest incidence is in the lactation phase followed by the dry period, as a consequence of injuries to the mammary gland or to the ceilings $[8,11]$. In mares with neoplasia of the mammary gland, unilateral or bilateral volume increase, pain, warm area, redness and suppurative serous discharge are frequently observed [13]. There are also reports of skin ulceration or necrosis [4]. Necrosis would be an impor- 


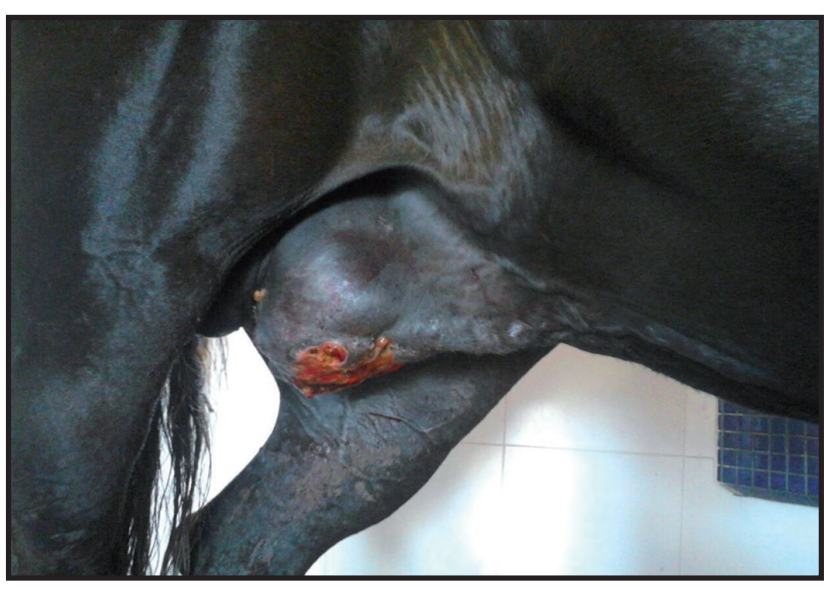

Figure 1. Tubulopapillary carcinoma of mammary gland in mare. Enlarged mammary gland with fistulated tumor mass.

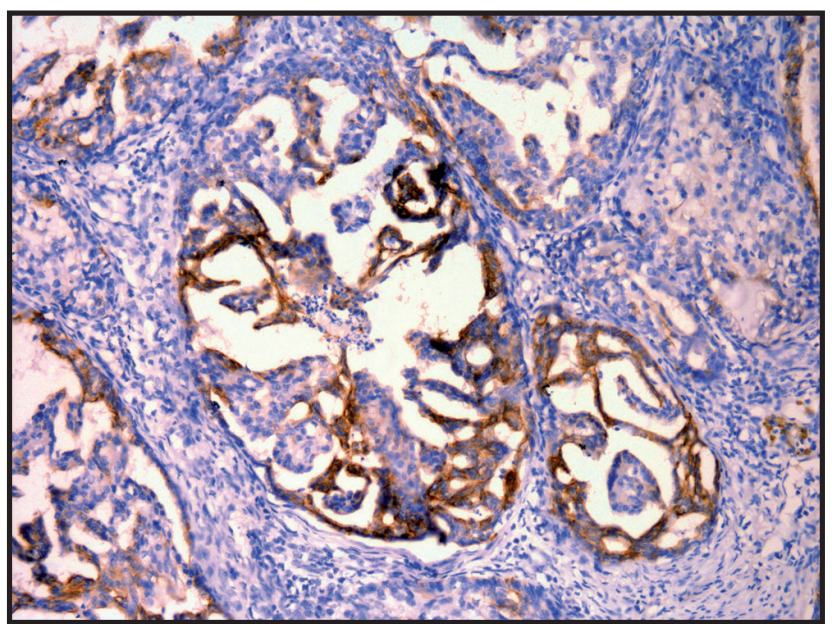

Figure 3. Mammary gland. Intense marking in cytoplasm of epithelial neoplastic cells for pancytokeratin. Immunohistochemistry, DAB chromogen and Harris hematoxylin [Obj. 40x].

tant clinical feature to aid in the diagnosis of mammary neoplasia [10], especially in cases of adenocarcinomas [3]. In the present report, the mare showed increased volume of the mammary gland, with focal hyperthermia, fistulated area and serum-blood secretion. The literature suggests a reserved prognosis for any mare presenting mammary neoplasia. In a study by Sysel et al. [16] in six mares with mammary neoplasia, the survival time after detection varied from three months to two years in mares not treated surgically and from three months to seven years in mares treated with radical mastectomy or hemimastectomy. The treatment of choice is the complete excision of the mammary glands and all accessible regional lymph nodes. This is a difficult procedure, which leads in some cases to wound dehiscence and postoperative infection. Long-term complications include recurrence of neoplasia or metastasis [13]. In the present case, the treatment

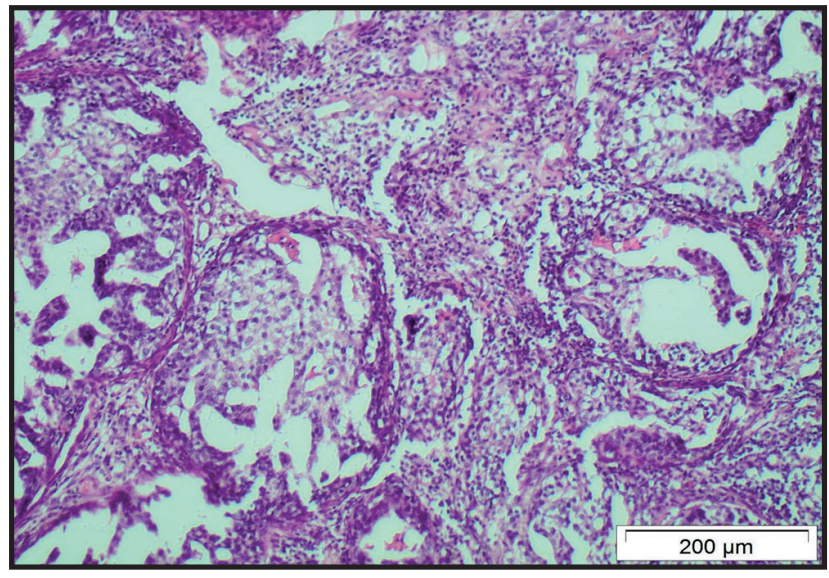

Figure 2. Proliferation of epithelial neoplastic cells arranged in tubules and papillary projections, hematoxylin and eosin. [Bar= $200 \mu \mathrm{m}$ ].

of choice was not performed and the mare died six months after diagnosis by biopsy.

Histopathology and immunohistochemistry were fundamental for the diagnosis of tubulopapillary carcinoma of the mammary gland in the present study. In Brazil, in two cases of tubulopapillary carcinoma in mare the diagnosis was made by histopathology and the findings were similar to the present case, however, the immunohistochemical characterization was not performed [3,14]. In an immunohistochemical study of equine mammary tissue, strong positivity was observed for pancytokeratin AE1/AE3 in normal alveolar and ductal cells, and poor positivity for AE1/AE3 and vimentin in neoplastic cells of invasive ductal mammary carcinoma (IDC) [5]. Curiously, in another case of IDC in a cow there were markedly positive markings for pancytokeratin in neoplastic cells [1]. In this case there was strong staining for pancytokeratin in tumor cells without coexpression with vimentin, which confirms the purely epithelial origin of the tumor, possibly of the alveolar epithelium [5]. Mammary neoplasiss in mares are rare, but should be considered in the diagnosis of mammary pathologies in this species.

\section{MANUFACTURERS}

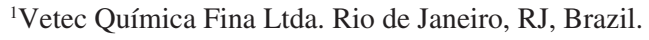
${ }^{2}$ Dako. Carpinteria, CA, USA.

Acknowledgments. This study was partially funded by the Coordenação de Aperfeiçoamento de Pessoal de Nível Superior - Brasil (CAPES).

Declaration of interest. The authors report no conflicts of interest. The authors alone are responsible for the content and writing of the paper. 


\section{REFERENCES}

1 Barbosa F.M.S., Dantas S.V.S., Nascimento H.H.L., Sobrinho J.P.A., Santos J.R.S., Kommers G.D. \& Lucena R.B. 2018. Carcinoma mamário ductal invasivo em uma vaca. Acta Scientiae Veterinariae. 46(Suppl 1): 288.

2 Bastianello S.S. 1983. A survey of neoplasia in domestic animal species over a 40-year period from 1935 to 1974 in the Republic of South Africa. III. Tumours occurring in pigs and goats. Onderstepoort Journal Veterinary Research. 50(3): 25-28.

3 Brito M.F., Seppa G.S., Teixeira L.G., Rocha T.G., França T.N., Hess T.M. \& Peixoto P.V. 2008. Mammary adenocarcinoma in a mare. Ciência Rural. 38(20): 556-560.

4 Goldschmidt M.H., Peña L. \& Zappulli V. 2017. Tumors of the mammary gland. In: Meuten D.J. (Ed). Tumors in Domestic Animals. 5th edn. Ames: John Wiley \& Sons, Inc., pp.723-765.

5 Heidrich H.J. \& Renk W. 1967. Diseases of the mammary glands of domestic animals. Philadelphia: Saunders, 371p.

6 Hirayama K., Honda Y., Sako T., Okamoto M., Tsunoda N., Tagami M. \& Taniyama H. 2003. Invasive ductal carcinoma of the mammary gland in a mare. Veterinary Pathology. 40: 86-91.

7 Knottenbelt D.C. 2003. The mammary gland. In: Knottenbelt D.C., Pascoe R., LeBlanc M. \& Lopate C. (Eds). Equine Stud Farm Medicine and Surgery. London: Saunders, pp.343-352.

8 McCue P.M. 1998. Neoplasia of the female reproductive tract. Veterinary Clinics of North America: Equine Practice. 14: 505-515.

9 Misdorp W. 2002. Tumors of the mammary gland. In: Meuten D.J. (Ed). Tumors in Domestic Animals. Ames: Blackwell, pp.575-606.

10 Prendergast M., Bassett H. \& Larkin HA. 1999. Mammary carcinoma in three mares. Veterinary Record. 144: 731732.

11 Reppas G.P., McClintock S.A., Canfield P.J. \& Watson G.F. 1996. Papillary ductal adenocarcinoma in the mammary glands of two horses. Veterinary Record. 138: 518-519.

12 Seahorn T.L., Hall G., Brumbaugh G.W., Honnas C.M., Lovering S.L. \& Snyder J.R. 1992. Mammary adenocarcinoma in four mares. Journal of the American Veterinary Medical Association. 200(11): 1675-1677.

13 Shank A.M. 2009. Mare mammary neoplasia: difficulties in diagnosis and treatment. Equine Veterinary Education. 20: 475-477.

14 Silva E.S.M., Monteiro L.N., Uliani R.C., Sequeira J.L., Rocha N.S. \& Prestes N.C. 2010. Carcinoma mamário em égua: achados clínicos e histopatológicos. Ars Veterinaria. 26(2): 120-123.

15 Spadari A., Valentini S., Sarli G., Spinella G. \& Millanta F. 2008. Mammary adenoma in a mare: clinical, histopathological and immunohistochemical findings. Equine Veterinary Education. 20(1): 4-7.

16 Sysel A.M., Moll H.D., Livesey M.A., Pringle J. \& Sloane D.E. 1993. Mastectomy in three of six cases of equine mammary neoplasia. Veterinary Surgery. 22: 401-402. 